\title{
Determination of persistent cyclic organochlorine residues in sediment slurry by microporous membrane liquid-liquid extraction and gas chromatography-mass spectrometry
}

\author{
Titus AM Msagati* and Bhekie B Mamba \\ Department of Chemical Technology, Faculty of Science, University of Johannesburg, PO Box 17011, \\ Doornfontein Campus, 2028, South Africa
}

\begin{abstract}
A method, using microporous membrane liquid-liquid extraction technique (MMLLE) and gas chromatography with an electron capture detector (GC-ECD) and gas chromatograph coupled to a mass spectrometer, was developed for the analysis of cyclic organochlorine pesticides (OCPs) and polychlorinated biphenyls (PCBs) in sediment slurry. The MMLLE extraction employed isooctane as the organic liquid that was immobilised in the hollow fibre pores and in the lumen, at optimal sample $\mathrm{pH}$ value of 2.0 for OCPs and 7 for PCBs. The effect of triton $\mathrm{x}-100$, in enhancing the dissolution of the compounds from sediment, was found to be optimal at a value of $0.15 \%$, while the ionic strength was optimal at a value of $0.01 \mathrm{M}$. Samples from coastlines along the Indian Ocean in the southern parts of South Africa were found to be contaminated with cis and trans chlordane at concentrations of up to $0.003 \mathrm{mg} / \mathrm{kg}$, while samples from northern parts were contaminated with $2,2^{\prime}, 4^{\prime}, 4$-tetrachloro-1,1'biphenyl at concentrations of up to $0.02 \mathrm{mg} / \mathrm{kg}$.
\end{abstract}

Keywords: Organochlorine pesticides, polychlorinated biphenyls, hollow fibre liquid phase micro-extraction, high performance liquid chromatography, mass spectrometry

\section{Introduction}

Persistent organic pollutants, for example, organochlorine pesticides (OCPs) and polychlorinated biphenyls ( $\mathrm{PCBs}$ ), are used worldwide for many purposes, including the control of plant diseases and disease vectors (Sanchez et al., 2006). However, they pose a significant toxicity problem due to their low volatility and slow degradation once exposed to the environment, causing high persistence (Hong et al., 1999; Tanabe et al., 1997). Organochlorine pesticides tend to be persistent in the environment because the presence of chlorine in an organic molecule reduces reactivity towards oxidation, and, being of low solubility in water; they are resistant to hydrolysis (Hong et al., 1999; Tanabe et al., 1997; Safe, 1990).

These persistent organic pollutants have a tendency to concentrate in fatty tissues and bio-accumulate in the food chain due to their high hydrophobicity (Chen et al., 2002). This bio-magnification tendency of OCPs is responsible for their occurrence at higher concentrations in organisms of higher trophic levels in food chains. Polychlorinated biphenyls are also suspected to be carcinogens.

In South Africa, the presence of agrochemical residues in the environment represents a serious and urgent challenge (London, 1992; 1995; Dalvie et al., 1999; Hassett et al., 1987; Grobler, 1994), because of the large diffusion potential of the agrochemical residues in the environment and their particular

\footnotetext{
* To whom all correspondence should be addressed.

䀅 +2711 559 6516; fax: +2711 5596425 ;

e-mail: tmsagati@uj.ac.za

Received 8 July 2010; accepted in revised form 13 December 2010.
}

chemical characteristics and properties which determine their persistence and toxicities in waters and soils. This makes the development of sensitive and selective analytical methods crucial, not only for the detection of the presence of these persistent organic pollutants and their degradation products, but also to study their distribution across the environmental compartments. Importantly, this will enable the establishment of the exact bio-available fraction for each pollutant in a given environment.

However, many of the known analytical procedures are designed to give a measure of the total contamination levels due to agrochemical residues, while the actual amounts available for absorption into the biological system may be lower, due to the interaction of each compound with the matrix molecules. Furthermore, bioavailability is dependent on the nature and properties of the chemical species polluting the environment, and the type of matrix in which pollutants are found (Dean and Scott, 2004).

In this work we have employed liquid phase microextraction using HF-LPME, commonly known as hollow fibre microporous membrane liquid-liquid extraction (HF-MMLLE) in GC-ECD, in order to study and determine the easily bio-available fraction of contaminants. Further confirmation of peaks by gas chromatography coupled to a mass spectrometer operating under electron ionization (GC-EI-MS) was done. Hollow fibre microporous membrane liquid-liquid extraction is a technique based on 2 phases (aqueous-organic): the donor phase (the aqueous sample to be extracted) and the membrane phase (an organic liquid held in the pores of a hydrophobic polymer). The extraction protocol essentially consists of 1 step, i.e., extraction of the analyte from the sample phase using an organic solvent (Pedersen-Bjergaard and Rasmussen, 1999). 


\section{Experimental}

\section{Chemicals and reagents}

Organochlorine pesticides and PCB standards ( $>99 \%$ purity) (Fig. 1; Table 1), were purchased from Riedel-de-Haën (SeelzeHannover, Germany). Pesticide-quality solvents ( $n$-hexane and toluene) and calcium chloride were purchased from Panreac (Barcelona, Spain). Sodium hydroxide pellets (98\%) were obtained from Saarchem (Krugerdorp, Africa). Stock standard solutions of individual compounds (with concentrations of 1000 $\mathrm{mg} / \ell$ ) were prepared, while triton $\mathrm{x}-100$ and hydrochloric acid were purchased from N.T. Laboratory Supplies, (Johannesburg, South Africa). A multicompound working standard solution ( $1 \mu \mathrm{g} / \mathrm{m} \ell$ concentration for each compound) was prepared by appropriate dilutions of the stock solutions $(1000 \mathrm{mg} / \ell)$ with hexane:toluene $(1: 1)$ and stored under refrigeration $\left(4^{\circ} \mathrm{C}\right)$.

\section{Sampling}

Samples were collected from several points along the northern Indian Ocean coastline of South Africa (along the Durban Harbour) and from the southern Indian Ocean coastlines, near East London. Surface sediment samples were collected with a clean stainless steel Van Veen grab. The first $5-10 \mathrm{~cm}$ sediment layer were scraped off into a stainless steel mixing bowl, and thoroughly mixed using a stainless steel spatula. The homogenized sample was then transferred into a rinsed solvent bowl (first with hexane and then with dichloromethane). Sediment samples were kept frozen until analysis was done. These samples were then air dried and sieved through a $<2 \mathrm{~mm}$ metal sieve in order to remove the coarser fractions. After drying, the samples were ground first with a mortar and pestle, before using a stainless steel blender, resulting in a fine powder.

\section{Preparation of slurry}

Sediment samples were collected, dried and ground to make homogeneous fine particles. The finely ground sediment samples were then mixed with $0.01 \mathrm{M} \mathrm{CaCl}_{2}(1 / 40(\mathrm{w} / \mathrm{v}))$. To enhance dissolution of PCBs and OCPs, a non-ionic surfactant, triton $\mathrm{x}-100(0.125 \%)$ was incorporated. The resulting solution was then extracted using the HF-LPME method.

\section{HF-LPME extraction procedure}

The hollow fibre tube used in this study was Q3/2 Accurel polypropylene hollow fibre membrane $(200 \mu \mathrm{m}$ wall thickness, $600 \mu \mathrm{m}$ inner diameter, $0.2 \mu \mathrm{m}$ pore size) obtained from Membrana $\mathrm{GmbH}$ (Wuppertal, Germany). The hollow fibres were impregnated with isooctane for about $5 \mathrm{~s}$ to open membrane pores and then immersed into $10 \mathrm{~m} \ell$ of sample which was subjected to stirring. The $100 \mathrm{~m} \ell$ syringes were used to support the hollow fibre during the extraction process, which proceeded for $30 \mathrm{~min}$ (see Fig. 2). When the extraction was complete, the syringe plunger was then depressed, flushing out the extracts from the lumen of the hollow fibre into a $100 \mathrm{~m} \ell$ insert fixed inside $1.5 \mathrm{~m} \ell$ sample vials.

\section{Gas chromatographic (GC-ECD) and gas chromatography - mass spectrometry (GC-EI-MS) analysis of HF-LPME extracts}

The Perkin Elmer GC system equipped with a manuallyoperated ECD detector (Valnut Creek, CA, USA), as well

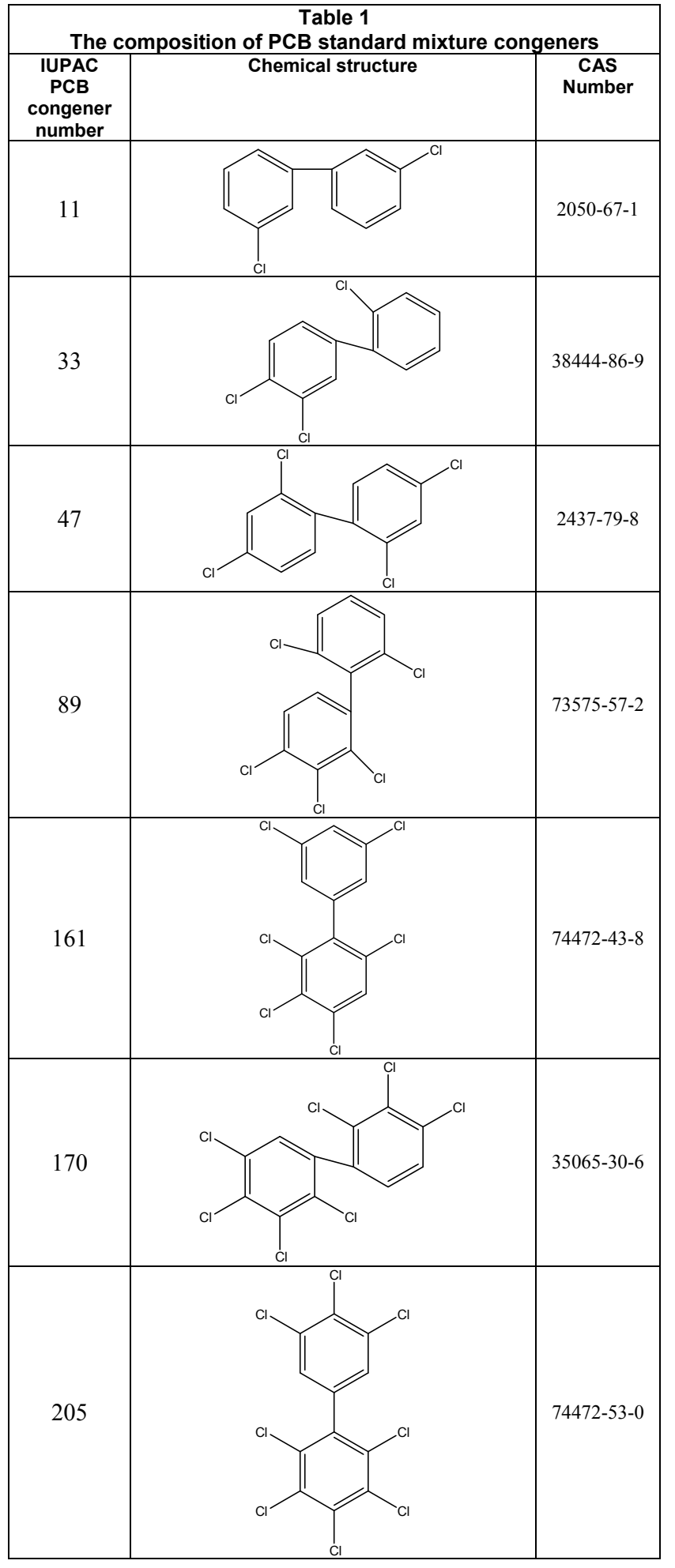

as HP Agilent $6890 \mathrm{GC} / 5973$ MS (Santa Clara, CA 95051 USA) were both used for the analysis of organochlorine pesticides. The column, DB-5 $(30 \mathrm{~m} \times 0.25 \mathrm{~mm}$ i.d. $\times$ $0.25 \mu \mathrm{m}$ film thickness) from Supelco (Bellefonte, PA, USA), was used in PE GC system and J\&W HP5-MS (30 $\mathrm{m} \times 250 \mu \mathrm{m}$ diameter $\times 0.25 \mu \mathrm{m}$ film thickness) was employed in the HP Agilent GC/5973 MS system. The flow rate of the carrier gas (nitrogen) was $1.5 \mathrm{~m} \ell / \mathrm{min}$ and the injection volume was $0.5 \mathrm{~m} \ell$. The glass liner was equipped 

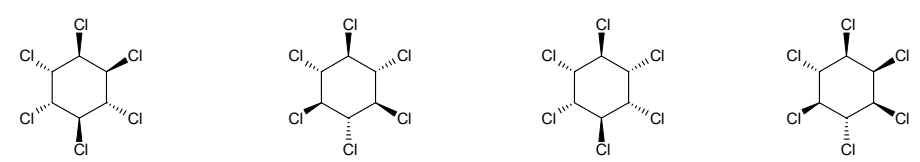

$\begin{array}{llll}\alpha-\mathrm{BHC}(\mathrm{CAS} \# \text { 319-84-6) } & \beta \text {-BHC (CAS \# 319-85-7) } & \gamma \text {-BHC (CAS \# 58-89-9) } & \delta \text {-BHC(319-86-8) } \\ \mathrm{C}_{6} \mathrm{H}_{6} \mathrm{Cl}_{6} & \mathrm{C}_{6} \mathrm{H}_{6} \mathrm{Cl}_{6} & \mathrm{C}_{6} \mathrm{H}_{6} \mathrm{Cl}_{6} & \mathrm{C}_{6} \mathrm{H}_{6} \mathrm{Cl}_{6}\end{array}$
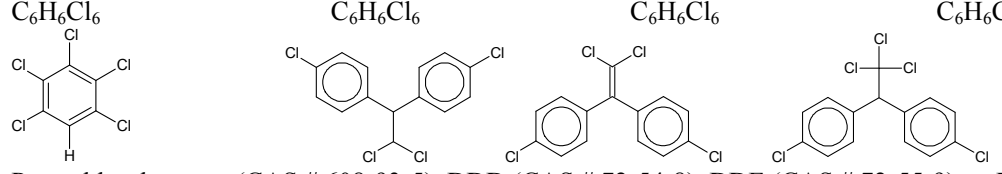

Figure 1

Chemical structures, names and CAS numbers and molecular formulas of the OCPS

Pentachlorobenzene (CAS \# 608-93-5) DDD (CAS \# 72-54-8) DDE (CAS \# 72-55-9) DDT (50-29-3)

$\begin{array}{llll}\mathrm{C}_{6} \mathrm{HCl}_{5} & \mathrm{C}_{14} \mathrm{H}_{10} \mathrm{Cl}_{4} & \mathrm{C}_{14} \mathrm{H}_{8} \mathrm{Cl}_{4} & \mathrm{C}_{14} \mathrm{H}_{9} \mathrm{Cl}_{5}\end{array}$
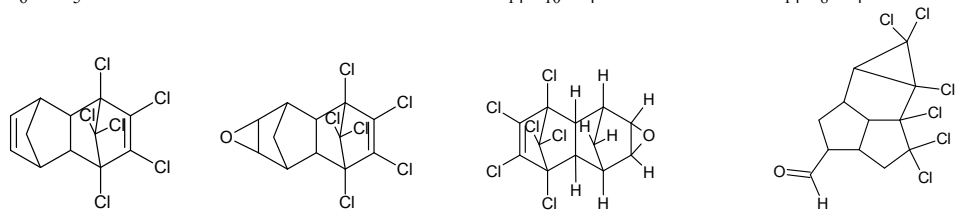

Aldrin (CAS \#309-00-2) Dieldrin (CAS \# 60-57-1) Endrin (CAS \#:72-20-8) Endrin aldehyde (CAS \# 7421-93-4)
$\mathrm{C}_{12} \mathrm{H}_{8} \mathrm{Cl}_{6}$
$\mathrm{C}_{12} \mathrm{H}_{8} \mathrm{Cl}_{6} \mathrm{O}$
$\mathrm{C}_{12} \mathrm{H}_{8} \mathrm{C}_{16} \mathrm{O}$
$\mathrm{C}_{12} \mathrm{H}_{8} \mathrm{Cl}_{6} \mathrm{O}$<smiles>ClC1=C(Cl)C2(Cl)C3C(Cl)C=CC3C1(Cl)C2(Cl)Cl</smiles>

Heptachlor (CAS \# 76-44-8)

$\mathrm{C}_{10} \mathrm{H}_{5} \mathrm{Cl}_{7}$
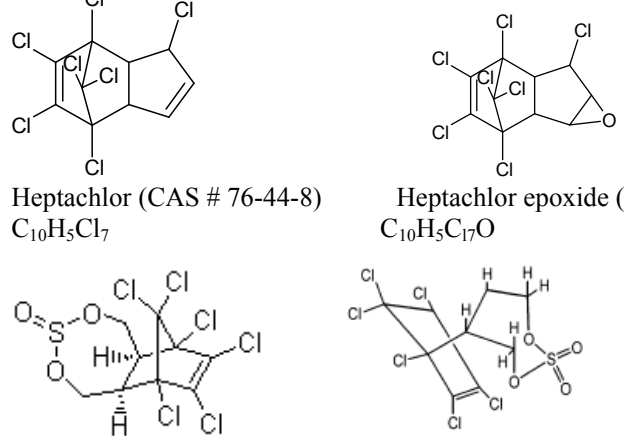

Heptachlor epoxide (CAS \# 1024-57-3) $\mathrm{C}_{10} \mathrm{H}_{5} \mathrm{C}_{17} \mathrm{O}$

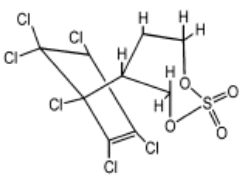

Endosulfan I (CAS \# 959-98-8) Endosulfan sulfate (CAS \# 1031-07-8) $\mathrm{C}_{9} \mathrm{H}_{6} \mathrm{Cl}_{6} \mathrm{O}_{3} \mathrm{~S}$

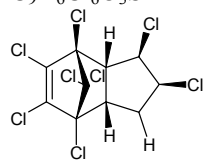
$\mathrm{C} 9 \mathrm{H} 6 \mathrm{Cl} 16 \mathrm{O} 4 \mathrm{~S}$

Cis-chlordane (CAS \# 5103-71-9) $\mathrm{C}_{10} \mathrm{H}_{6} \mathrm{Cl}_{8}$

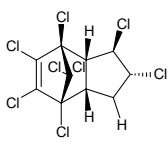

Trans-chlordane (CAS \# 5103-71-9) $\mathrm{C}_{10} \mathrm{H}_{6} \mathrm{Cl}_{8}$

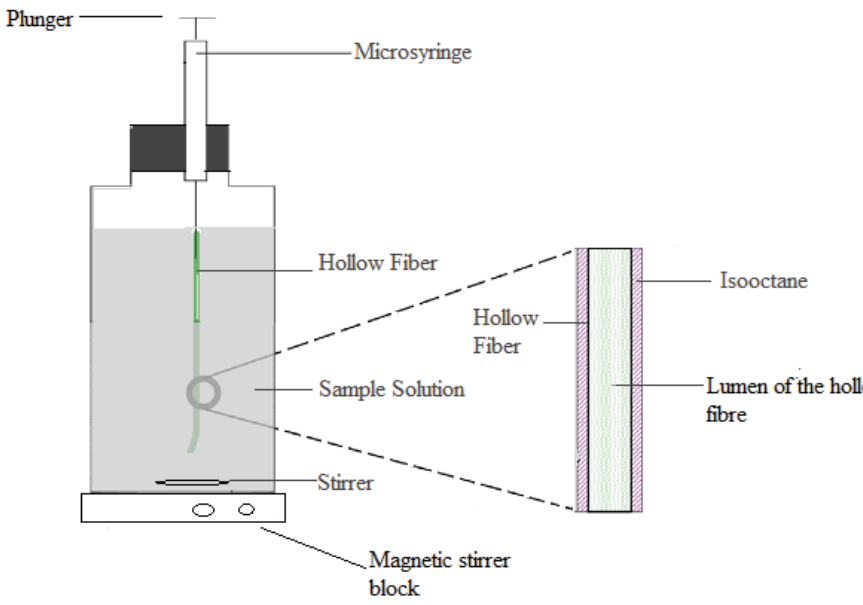

Figure 2

Experimental set-up for the hollow fibre liquid phase microextraction (HF-LPME)

with a plug of carbofrit (Resteck, Bellefonte, PA, USA). The mass spectrometer was operated under EI mode, Scan 35 to $500 \mathrm{amu}$, Source $230^{\circ} \mathrm{C}$, Quad $150^{\circ} \mathrm{C}$, and solvent delay $4 \mathrm{~min}$.

\section{Quality assurance and method validation}

The quality assurance and method validation consisted of the analysis of blank samples, measurements of reproducibility and repeatability parameters, as well as the analysis of certified reference materials. The certified reference material (CRM-No. IAEA 417 for organochlorine compounds (OCPs \& PCBs) and petroleum hydrocarbons in sediment samples (Analytical Quality Control Services, International Atomic Energy Agency, Vienna, Austria) was used to validate the analytical method. The results of PCBs congeners from the tests (an average of $1.03 \pm 0.07$ $\mathrm{mg} / \mathrm{kg}$ ) were in good agreement with the certified values. Similarly, the results of OCPs from the tests conducted were found to be in good agreement with the certified values with average relative deviations ranging between 1.4 and $16 \%$. The recoveries for both PCBs and OCPs were in the range $72-91 \%$ for all compounds for the spiked samples.

\section{Results and discussion}

\section{Optimisation of Parameters in the HF-LPME of OCPs and PCBs}

Several analytical parameters had to be optimised to enhance the extractability of OCPs and PCBs from sediment. Factors studied included: amount of triton $\mathrm{x}-100$, ionic strength of the $\mathrm{CaCl}_{2}$, sample $\mathrm{pH}$, extraction time and the type of organic solvent.

\section{Influence of triton $\mathrm{x}-100$ surfactant and concentration of $\mathrm{CaCl}_{2}$}

The inclusion of triton $\mathrm{x}-100$ was found to significantly enhance the dissolution of OCPs and PCBs from the sediment to the solution. As the percentage of triton $\mathrm{x}-100$ was increased, more of the OCPs and PCBs were brought into the solution and hence increased extraction efficiency by the hollow fibre.

The ionic strength of the $\mathrm{CaCl}_{2}$ solution was found to influence the dissolution of OCPs and PCBs. As the concentration was increased from $0.005 \mathrm{M}$ to $1 \mathrm{M}$, the extraction efficiency was increased and an optimal was obtained at $0.01 \mathrm{M}$. 


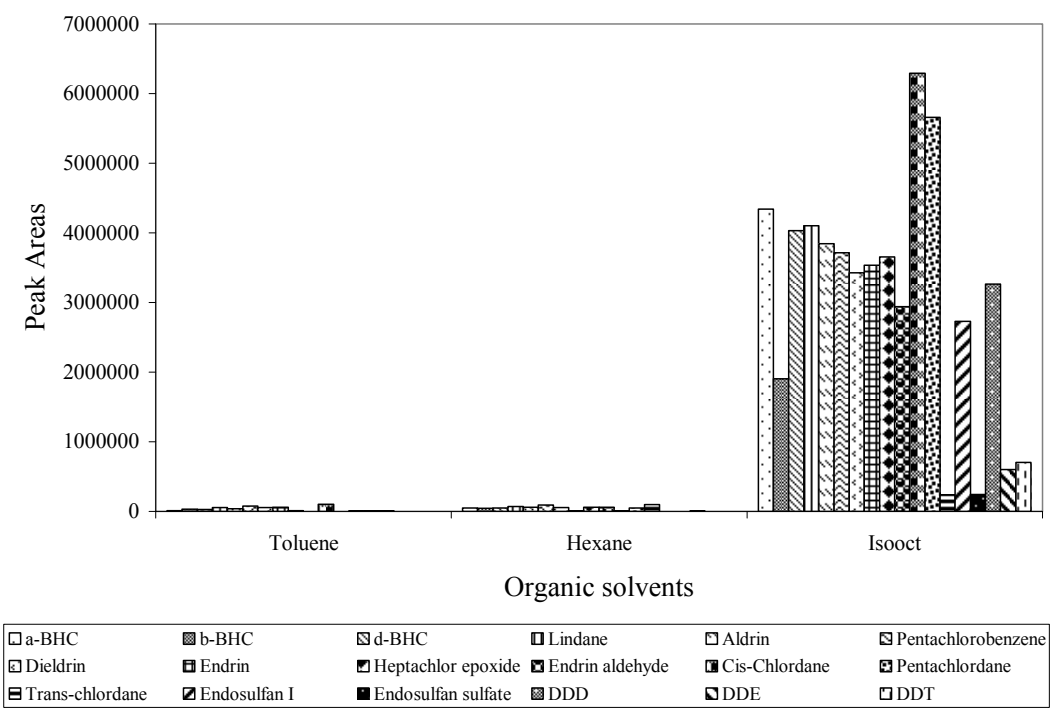

Figure 3

Choice of the organic solvent in the HF-LPME of OCPS

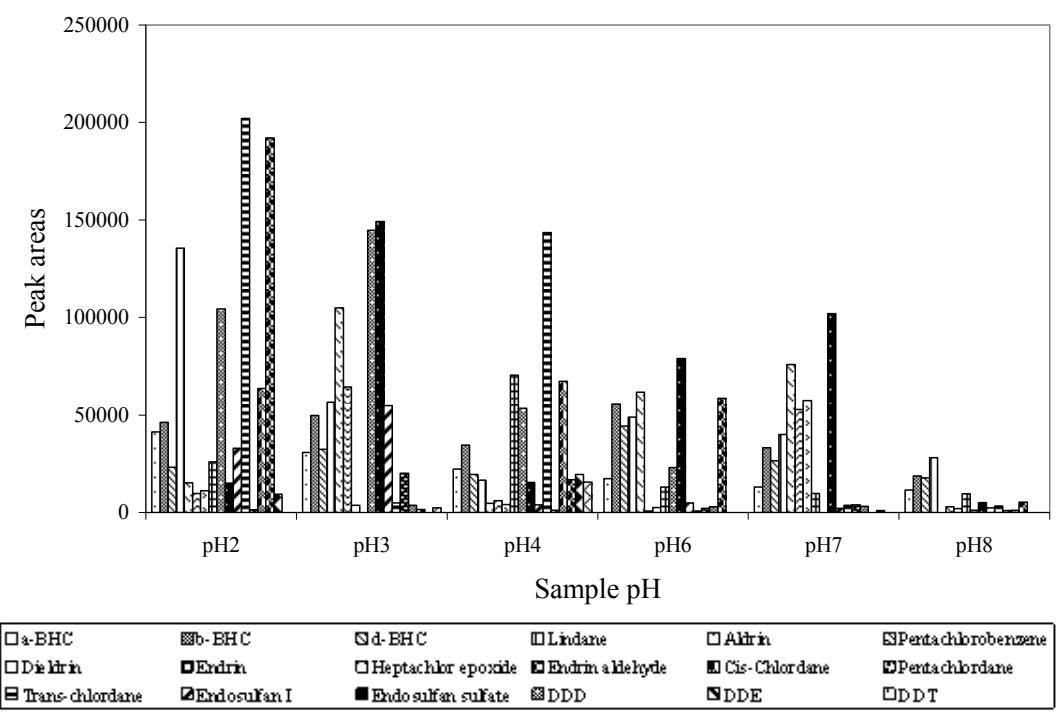

Figure 4

Influence of sample $\mathrm{pH}$ on the HF-LPME of slurry samples for OCPs

Influence of sample $\mathrm{pH}$

It is known that sample pH has an influence on the enrichment of analyte in the membrane extraction process. If the $\mathrm{pH}$ value of the sample is equal to, or slightly higher than, the pKa value of the analyte, the analyte molecules in the sample will be in ionic form. The ionic form would not be suitable for entrapment of analytes by the liquid membrane (Jönsson and Mathiasson, 1999a;b).

In this work, the variation of sample $\mathrm{pH}$ with the analyte enrichment, as measured by the peak areas for sample solutions of 1 $\mathrm{m} \ell / \mathrm{kg}$, was investigated for both the matrices (slurries) in which PCBs and OCPs were contained. With OCP slurry, the sample $\mathrm{pH}$ was varied from $\mathrm{pH} 2$ to $\mathrm{pH} 8$, while for PCB slurry the sample $\mathrm{pH}$ was varied from $\mathrm{pH} 4$ to $\mathrm{pH} 10$. The results showed that the analyte enrichment of compounds increased with $\mathrm{pH}$ to different optimal $\mathrm{pH}$ values (Fig. 4); thus the enrichment was sample $\mathrm{pH}$ dependent.

Figure 4 shows that most of the OCP slurries studied experienced higher enrichment at lower $\mathrm{pH}(2-4)$. These OCPs included, aldrin, cis chlordane, trans chlordane, dieldrin, endrin, DDD, DDE, and DDT. Others, like a-BHC, b-BHC, d-BHC, endrin and endrin aldehyde, experienced enrichment over an acidic $\mathrm{pH}$ and performed poorly at $\mathrm{pH}$ above neutral, which suggests that they are not stable at those $\mathrm{pH}$ ranges. The OCP slurry enrichment was found to drop drastically especially at alkaline $\mathrm{pH}$ values. With PCBs, most compounds were found to have highest enrichment at neutral pHs (data not shown). The optimal $\mathrm{pH}$ values chosen were therefore $\mathrm{pH} 2$ for OCPs and $\mathrm{pH} 7$ for PCBs.

\section{Optimisation of extraction time}

\section{Selection of organic solvent}

The composition of the organic liquid membrane is known to play an essential role in governing the extraction efficiency and selectivity of the analyte (Jönsson and Mathiasson, 1999a). For higher analyte enrichment, it is desired that the partition coefficient of the analyte should be as large as possible in comparison with interferents (Jönsson and Mathiasson, 1999b); it should have a low water solubility and the analytes to be extracted must be soluble in it. Therefore, 3 liquid membranes were tested in an attempt to identify suitable liquid membranes for the extraction of these compounds from the sediment slurry. These included: hexane (polarity index 0.1 ), toluene (polarity index 2.4) and isooctane (polarity index 0.1). Of these, isooctane was found to be the most suitable solvent (Fig. 3) as it extracted the majority of OCPs and PCBs at a relatively higher order than the other two solvents, which showed a tendency to evaporate faster while having a relatively slightly higher water solubility.
The effect of extraction time was studied using a $1 \mathrm{mg} / \ell$ sample solution of a mixture of both OCPs and PCBs at constant stirring speed of $400 \mathrm{r} / \mathrm{min}$. The results obtained showed that the effect of time was important and demonstrated that the enrichment of analyte was time dependent. At given conditions the enrichment was optimal at about $30 \mathrm{~min}$. Beyond that time ( $30 \mathrm{~min})$, the extraction efficiency started to decrease. Therefore $30 \mathrm{~min}$ was taken as the optimal extraction time for all the OCP and PCBs.

\section{Linearity in the extraction process}

To investigate linearity of the membrane extraction/enrichment process, blank samples were spiked with varying concentration of standards of OCPs and PCBs. The linearity of the membrane extraction method was then determined by injecting $1 \mathrm{~m} \ell$ standard solutions with concentrations ranging between 0.2-1 $\mathrm{m} \ell / \mathrm{kg}$ of both OCPs and PCBs. The blank matrices as well as the spiked samples were also extracted at optimal conditions and determined by GC-ECD and GC-MS. Linear calibration 


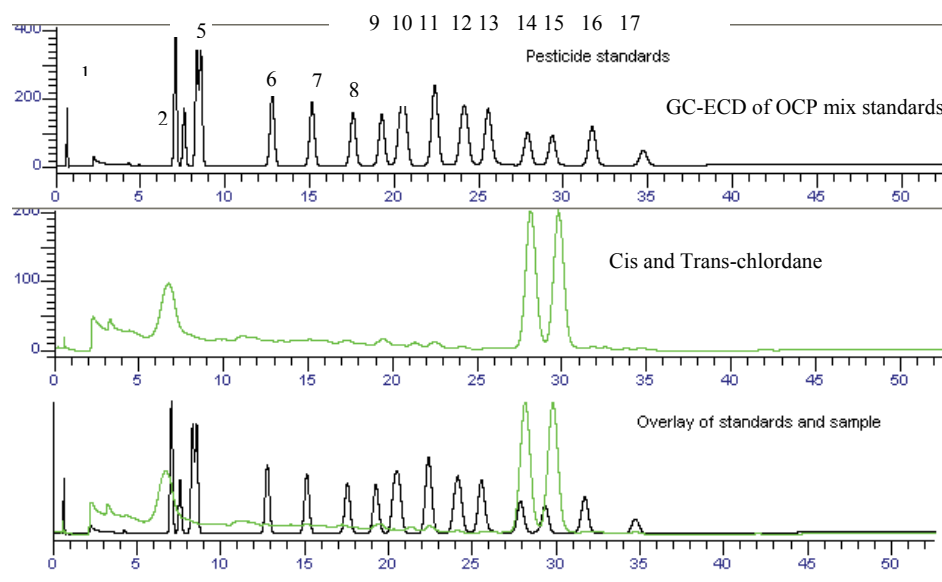

Identity of peaks: $\mathbf{1}=1,2,3,4,5-$ Pentachlorobenzene, $\underline{\mathbf{2}}=\alpha$-BHC; $\underline{\mathbf{3}}=\gamma$-BHC; $\underline{\mathbf{4}}=\beta$-BHC; $\underline{\mathbf{5}}=$ Heptachlor; $\underline{\mathbf{6}}=\delta$-BHC; $\underline{\mathbf{5}}=$ DDD $\underline{\mathbf{z}}=$ DDE; $\underline{\mathbf{8}}=$ DDT; $\underline{\mathbf{9}}=$ Aldrin; $\underline{\mathbf{1 0}}=$ Heptachlor; $\underline{\mathbf{1 1}}$, Endrin; $\underline{\mathbf{1 2}}=$ Dieldrin; $\underline{\mathbf{1 3}}=$ Endosulfan I; $\underline{1} 4=$ Trans-chlordane; $\underline{\mathbf{1 5}}=$ Cis chlordane; $\underline{\mathbf{1 6}}=$ Endosulfan sulfate, $\underline{\mathbf{1 7}}=$ Methoxychlor
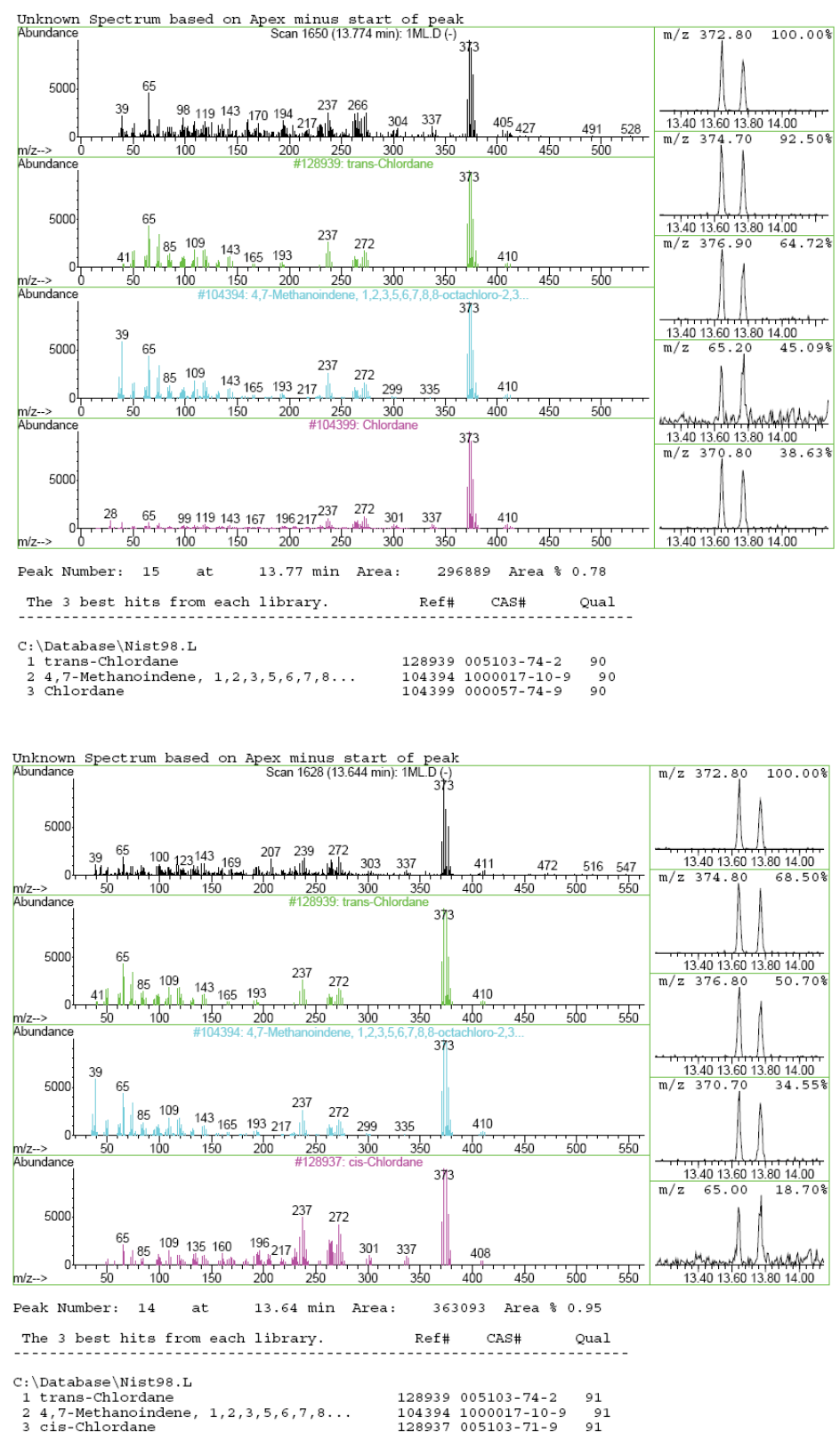

graphs were constructed for average peak areas versus concentration. Good linearity was found in the concentration range studied, with determination coefficients higher than 0.99 .

\section{Separation and detection by GC-ECD and GC-EI-MS}

The gas chromatographic separation of the OCPs and PCBs was successfully achieved and the identification of the individual peaks was aided and validated by the MS for the environmental samples (Figs 5a-c for OCPs and Figs. $6 \mathrm{a}$ and $\mathrm{b}$ for PCBs).

\section{Analysis of sediment samples from southern and northern coastline areas in South Africa.}

The developed method was applied to samples that were collected from the southern and northern coastline areas of South Africa. Two OCPs, namely, cis and trans chlordane, were detected from sediment samples in southern coastline areas near East London at concentrations of $0.003 \mathrm{mg} / \mathrm{kg}$, and $1 \mathrm{PCB}, 2,2^{\prime}, 4^{\prime}, 4$ tetrachloro-1,1'biphenyl, was also detected from the sediment samples collected from the northern coastline near the Durban harbour area, at concentrations of $0.02 \mathrm{mg} / \mathrm{kg}$. The OCPs might have emanated from either agriculture-related activities or fumigation activities in the neighbouring areas. The PCB contamination of the harbour may originate from the PCB-bearing oil and sediments that have accumulated in the structure over a period of time. The augmented PCB migration from the bedrock beneath may also have been responsible for the contamination. Another possible source of PCB contamination in harbours may be from painting of ships. The values obtained were lower than the threshold limits set by EPA, which is $2 \mathrm{mg} / \mathrm{kg}$ (FAO/WHO, 1986).

\section{Conclusions}

The method developed involving HF-LPME, GC-ECD and GC-EI-MS was shown to be successful, working within a reduced time frame as compared to other methods, such as soxhlet extraction, which not only are longer and more tedious but extract the total and not merely the bio-available fraction of the contaminants. This method's attractive features, such as simplicity, the use of minimal organic solvents and high extraction efficiencies and enrichment factors, have added value to the analysis protocol of OCPs and PCBs in sediment slurry.

Figure 5a (Top left)

GC-ECD chromatograms of standards and sample from East London

Figure 5b (Middle left)

GC-EI-MS showing the identification of transchlordane in the samples from East London Figure 5c (Bottom left)

GC-El-MS Showing the identification of cis-chlordane in samples from East London 

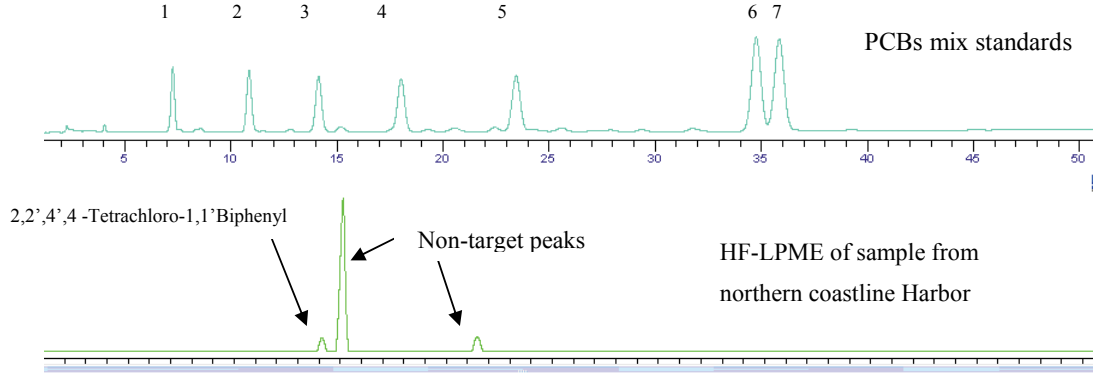

Identity of Peaks: $\underline{\mathbf{1}}=3,3$ '-Dichloro-1,1'-Biphenyl; $\underline{\mathbf{2}}=$ = 2,3', 4'-Trichloro-1,1'-Biphenyl;

$\mathbf{3}=2,2^{\prime}, 4,4^{\prime}$-Tetrachloro-1,1'Biphenyl; 4 =2,2',3',4,6'-Pentachloro-1,1'-Biphenyl;

$\underline{\mathbf{5}}=2,3,3^{\prime}, 4,5^{\prime}, 6$-Hexachloro-1,1'-Biphenyl; $\underline{\mathbf{6}}=$ 2,2',3,3',4,4',6-Heptachloro-1,1'-Biphenyl;

$\underline{\mathbf{7}}=2,3,3^{\prime}, 4,4^{\prime}, 5,5^{\prime}, 6$-Octachloro-1,1'-Biphenyl

Figure 6a

GC-ECD chromatograms showing the identification of PCB congener No. 47 in Durban Harbour sediment samples
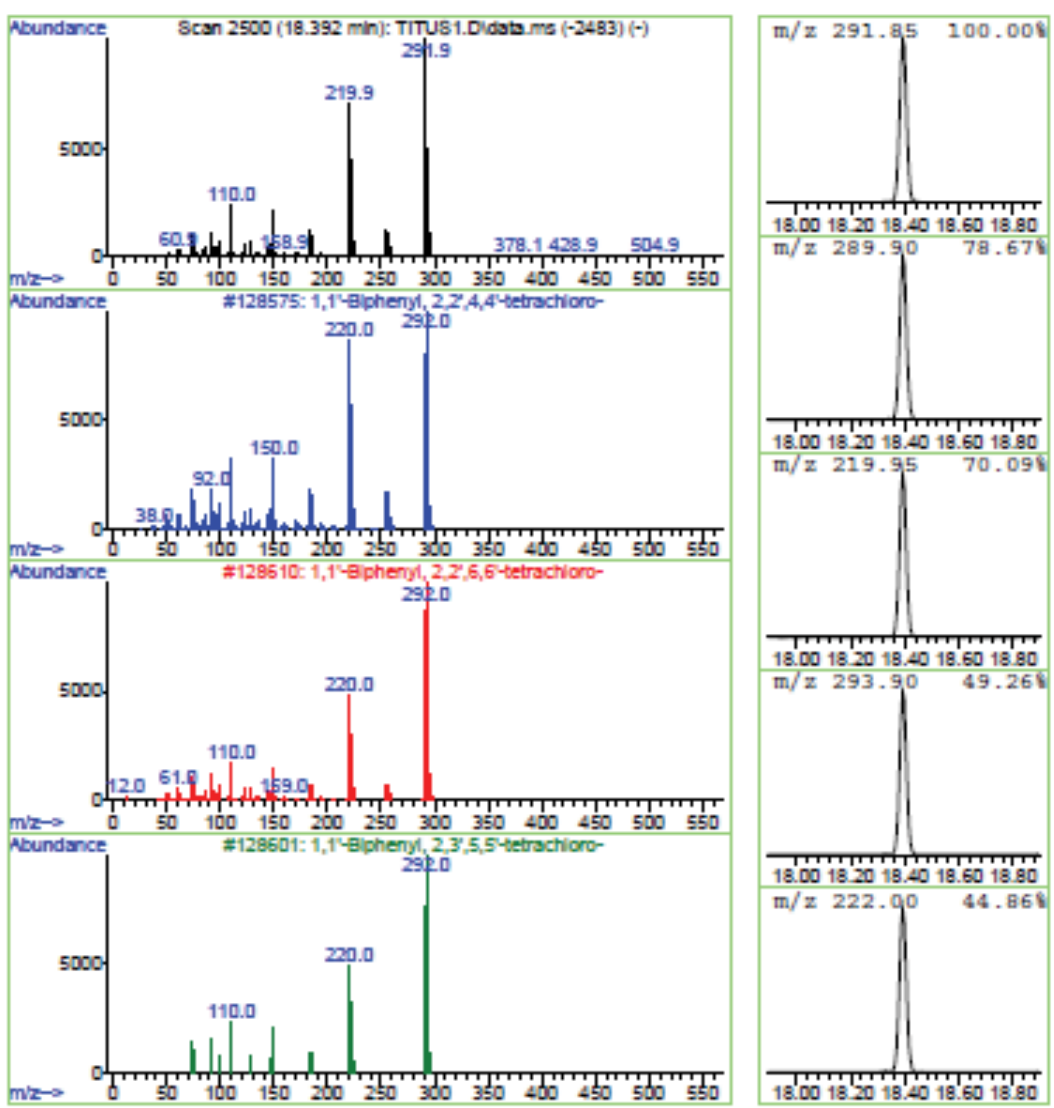

Figure $6 b$

GC-El-MS chromatograms showing the identification of 2,2',4',4-tetrachloro1,1'biphenyl (PCB congener No. 47) in Durban Harbour sediment samples

\section{Acknowledgements}

Financial support from NRF-Swedish is gratefully appreciated.

\section{References}

CHEN W, ZHANG L, XU L, WANG X, HONG L and HONG H (2002) Residue levels of HCHs, DDTs and PCBs in shellfish from coastal areas of east Xiamen Island and Minjiang Estuary, China. Mar. Poll. Bull. 45 385-390.
DALVIE MA, WHITE N, RAINE R, MYERS JE, LONDON L, THOMPSON $M$ and CHRISTIANI L (1999) Long-term respiratory health effects of the herbicide, paraquat, among workers in the Western Cape. Occup. Environ. Med. 56 (6) 391-396.

DEAN JR and SCOTT WC (2004) Recent developments in assessing the bioavailability of persistent organic pollutants in the environment. Trends Anal. Chem. 23 (9) 609-618.

FAO/WHO (Food and Agriculture Organization/World Health Organization) (1986) Maximum Limits for Pesticide Residues Vol. XIII (2nd edn.). Codex Alimentarius, Rome.

GROBLER DF (1994) A note on PCBs and chlorinated hydrocarbon pesticide residues in water, fish and sediment from the Olifants River, Eastern Transvaal, South Africa. Water SA 20 (3) 187-194.

HASSETT AJ, VILJOEN PT and LIEBENBERG JJE (1987) An assessment of chlorinated pesticides in the major surface water resources of the Orange Free State during the period September 1984 to September 1985. Water SA 13 (3) 133-136.

HONG H, CHEN W, XU L, WANG X and ZHANG L (1999) Distribution and fate of organochlorine pollutants in the Pearl River Estuary. Mar. Poll. Bull. 39 376-382.

JÖNSSON JÅ and MATHIASSON L (1999a)

Liquid membrane extraction in analytical sample preparation. I. Principles. Trends Anal. Chem. 18 318-325.

JÖNSSON JÅ and MATHIASSON L (1999b) Liquid membrane extraction in analytical sample preparation. II. Aplications. Trends Anal. Chem. 18 325-334.

LONDON L (1995) General patterns of agrochemical usage in the southern region of South Africa. S. Afr. J. Sci. 91 509-514

LONDON L (1992) Agrichemical hazards in the South African farming sector. S. Afr. Med. J. 81 (11) 560-564.

PEDERSEN-BJERGAARD S and RASMUSSEN KE (1999) Liquid-liquid-liquid microextraction for sample preparation of biological fluids prior to capillary electrophoresis. Anal. Chem. 71 2650-2656.

SAFE S (1990) Polychlorinated biphenyls (PCBs), dibenzo-p-dioxins (PCDDs), dibenzofurans (PCDFs), and related compounds: Environmental and mechanistic considerations which support the development of toxic equivalency factors (TEFs). Crit. Rev. Toxicol. 21 51-88.

SANCHEZ R, VAZQUEZ A, VILLENALTAMIRANO J, and VILLEN J (2006) Analysis of pesticide residues by on-line reversed-phase liquid chromatography-gas chromatography in the oil from olives grown in an experimental plot. J. Sci. Food Agric. 86 (1) $129-134$.

TANABE S, MADHUSREE B, OZTURK AA, TATSUKAWA R, MIYAZAKI N, OZDAMAR E, ARAL O and SAMSUN O (1997) Persistent organochlorine residues in harbour porpoise (Phocoena phocoena) from the Black Sea. Mar. Poll. Bull. 34 338-347. 